Tieming Xiang

Jixiang Yi

Wuxiong $\mathrm{Li}$

https://doi.org/10.21278/TOF.42107

ISSN 1333-1124

eISSN 1849-1391

\title{
FIVE-AXIS NUMERICAL CONTROL MACHINING OF THE TOOTH FLANK OF A LOGARITHMIC SPIRAL BEVEL GEAR PINION
}

\begin{abstract}
Summary
In this paper, the production of a logarithmic spiral bevel gear prototype is illustrated by the manufacture of the gear pinion. Firstly, the conical gear body of a logarithmic spiral bevel gear pinion was shaped on a C6140A1 lathe. A kinematic model of a five-axis vertical machining centre DMG DMU40 monoBLOCK, with the position and orientation of each axis relative to the movement of the workpiece, was created. In addition, the processing coordinate transformation formula between the workpiece coordinate system and the cutter coordinate system was devised. The cutter location file was converted to the numerical control code of the DMG DMU40 monoBLOCK. Finally, the pinion of a logarithmic spiral bevel gear was machined on the DMG DMU40 monoBLOCK as a prototype to be used in further research of the logarithmic spiral bevel gear.
\end{abstract}

Key words: $\quad$ logarithmic spiral bevel gear; five-axis vertical machining centre; cutter path; post processor coordinate transformation; DMU40 monoBLOCK

\section{Introduction}

The process technology of a conventional spiral bevel gear (SBG) commonly used in automotive industry is monopolized by Gleason, Oerlikon and Klingelnberg [1-3]. Generally speaking, there are mainly two types of machine tools: the professional traditional mechanical machine tool and the professional computer numerical control (CNC) machine tool [4-7]. The SBG pinion is machined by using a professional traditional mechanical machine tool which has a complex mechanism, such as a cutter turning mechanism, a degeneration mechanism, and a spiral motion mechanism [8-9]. Professional CNC machine tools such as the Gleason Free-Form PHOENIX machine tools, machine conventional SBGs through the numerical control (NC) code. Five-axis general CNC machine tools can complete a multi-process by one clamping and can process any complex surface in theory. [10-14].

Logarithmic spiral bevel gear (LSBG) is a new kind of SBG with the characteristics of using a conical logarithmic spiral curve as the tooth trace curve and an involute as the tooth profile curve [15-16]. The spiral angle at a point defined by the angle between the tangent direction of the conical logarithmic spiral curve and the cone generatrix direction is constant [17]. The LSBGs have better transmission characteristics compared with the conventional 
SBGs [18-20] because of the constant spiral angle. Q.Li made a high-tooth LSBG prototype [21-25] by using a general five-axis CNC machine tool at the Inner Mongolia University of Science and Technology of China, but the tapered teeth of the LSBG was not mentioned. In this study, a LSBG pinion prototype with tapered teeth was made on a DMG DMU40 monoBLOCK five-axis vertical machining centre.

\section{Preparation for the machining of an LSBG pinion}

\subsection{Analysis of the manufacturing process}

The drawing of the LSBG pinion to be formed is shown in Figure 1.

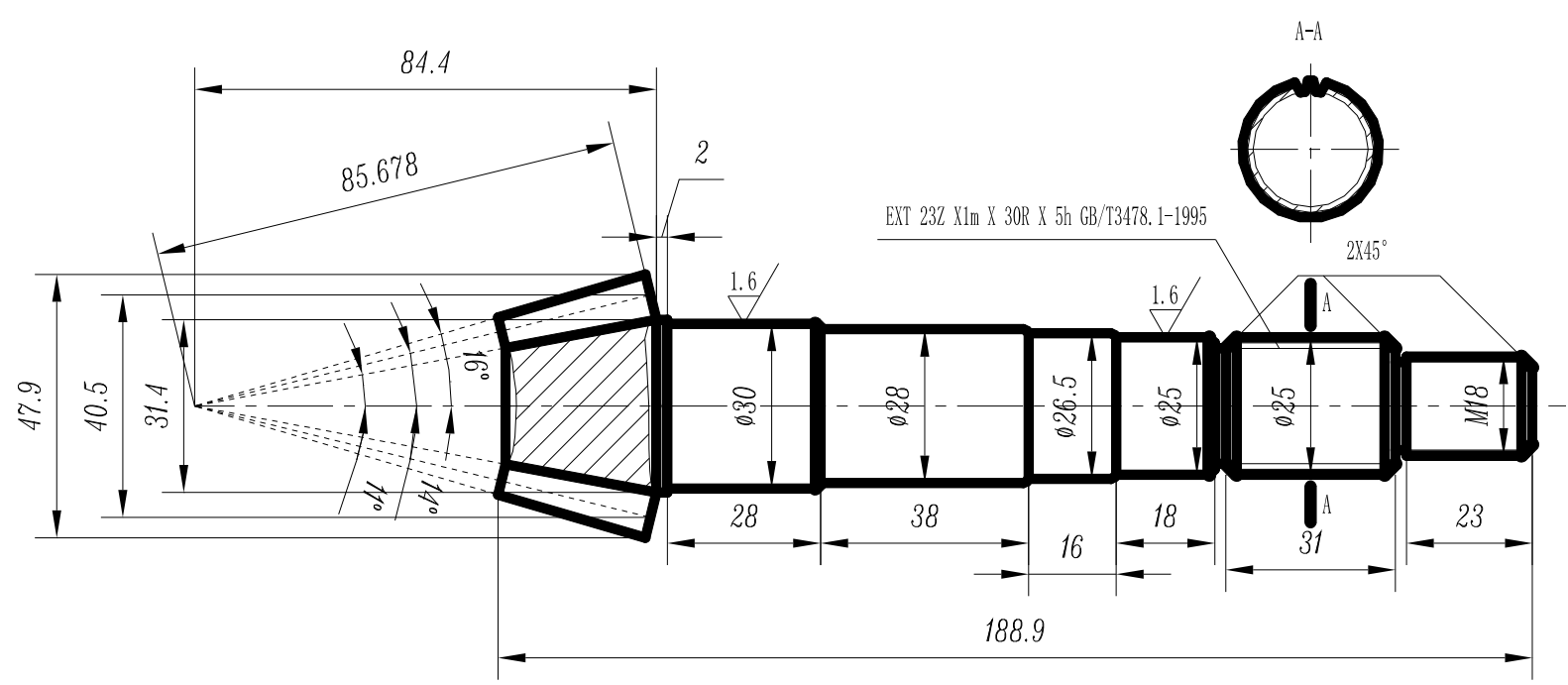

Fig. 1 The drawings of the LSBG pinion to be formed

The relevant parameters of the pinion are shown in Table 1. Medium carbon steel 45 was used as the material for the production of the LSBG pinion prototype. The stages in the process of the LSBG pinion forming are as follows. First, blanking was done and then the locating datum was processed on the conventional lathe by using a three-jaw chuck for clamping. The rough machining of the shaft shoulder of the LSBG pinion was done. The fine machining of the shaft shoulder important for mounting and positioning is also necessary. Next, the LSBG gear blank can be produced by using the shaft neck and the shaft shoulder as the locating data, and then the thread on the shaft of the LSBG pinion was produced. The spline of the LSBG pinion shaft was produced on a professional machine tool, and the tooth surface of LSBG pinion was produced on a general five-axis vertical machining centre. The difficulty in producing the tooth surface of the LSBG pinion is not less severe than that in producing a blade of an aircraft engine, a propeller blade of a ship or a submarine because of the complex logarithmic spirally curved surface [26-31]. Therefore the general five-axis vertical machining centre DMG DMU40 monoBLOCK was employed to form the LSBG pinion in this study.

\subsection{Forming of the conical gear body}

The conical gear body of the LSBG pinion were formed on a conventional C6140A1 lathe by using a three-jaw chuck for clamping. The radial positioning datum is the rotary centre axis line of the workpiece which is the line of the three-jaw chuck centre and the line of lathe spindle centre. 
Table 1 Parameters of the LSBG pinion

\begin{tabular}{|l|c|c||l|c|c|}
\hline Parameter & $\begin{array}{c}\text { Symbol } / \\
\text { Unit }\end{array}$ & Value & Parameter & $\begin{array}{c}\text { Symbol } / \\
\text { Unit }\end{array}$ & Value \\
\hline Number of teeth & $\mathrm{z}$ & 9 & Pitch circle diameter & $D_{\mathrm{p}} / \mathrm{mm}$ & 40.5 \\
\hline $\begin{array}{l}\text { Exterior transverse } \\
\text { modulus }\end{array}$ & $m / \mathrm{mm}$ & 4.5 & Pressure angle & $\alpha_{\mathrm{n}} /\left(^{\circ}\right)$ & 20 \\
\hline Shaft angle & $\sum /\left(^{\circ}\right)$ & 90 & Spiral angle & $\beta_{\mathrm{m}} /\left(^{\circ}\right)$ & 35 \\
\hline Reference cone angle & $\delta /\left(^{\circ}\right)$ & 13.6713 & $\begin{array}{l}\text { Face } \\
\text { coefficient }\end{array}$ & $\Phi_{\mathrm{R}}$ & 0.3268 \\
\hline Face width & $b / \mathrm{mm}$ & 28 & Addendum & $h_{\mathrm{a}} / \mathrm{mm}$ & 3.825 \\
\hline Rotation direction & & Left & Dedendum & $h_{\mathrm{f}} / \mathrm{mm}$ & 4.671 \\
\hline
\end{tabular}

\subsection{Five-axis vertical machining centre, DMU40 monoBLOCK}

DMG DMU40 monoBLOCK, a five-axis vertical machining centre is one of the most efficient five-axis vertical machining centres among machining centres in the same price range. Its optimal matching spindle rotation velocity ranges from $10000 \mathrm{rpm}$ to $42000 \mathrm{rpm}$. This machining centre uses the B axis as the fast dynamic NC milling head with a wide swing angle range of -95 degrees to +30 degrees. The most important component of the five-axis vertical machining centre is the spindle system which is shown in Figure 2. The NC control system of the DMU40 monoBLOCK is Heidenhain iTNC 530 which is suitable for drilling, boring and milling.

\section{Generation of the cutter path}

\subsection{Basic principles}

A ball-end cutter was employed, in the machining of LSBG pinion. The relation between the ball-end cutter and the machined surface is shown in Figure 3. Overcutting, undercutting and collision [32-33] may occur during the machining of the LSBG pinion on a five-axis vertical machining centre. Theoretically speaking, no matter how the ball-end cutter path is planned, a collision between the cutter tip and the workpiece will not happen as long as the radius of the ball-end cutter is smaller than the radius of curvature of the surface being machined [34-39].

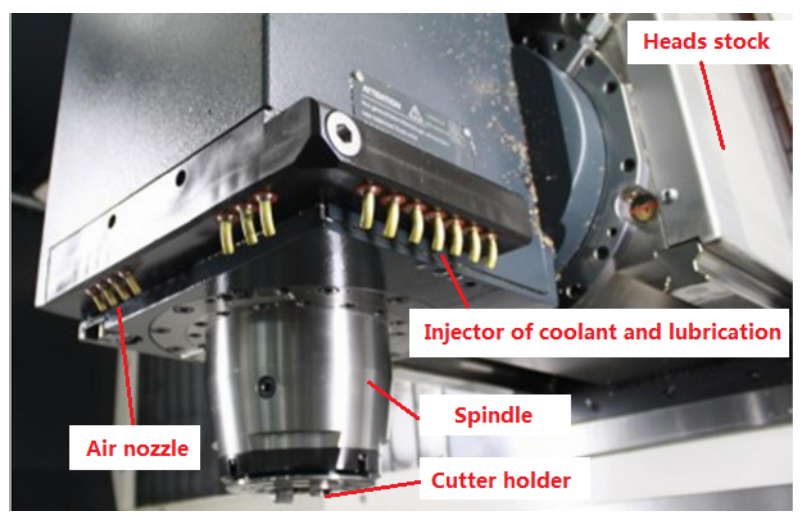

Fig. 2 The spindle system of DMU40 monoBLOCK

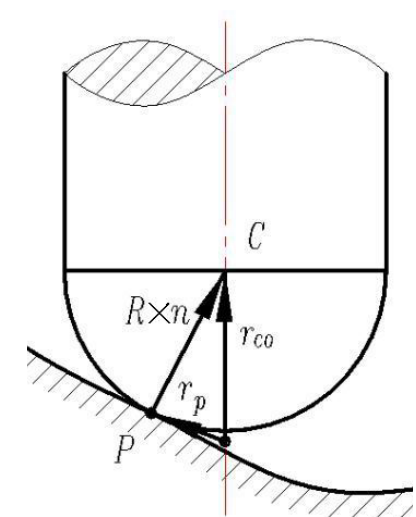

Fig. 3 Cutter and the machined surface

The equation of the cutter position calculation is as follows:

$$
\mathbf{r}_{C_{o}}=\mathbf{r}_{p}+R \times \mathbf{n}
$$


where $\mathbf{r}_{C_{o}}\left(x_{C_{o}}, y_{C_{o}}, z_{C_{o}}\right)$ is the vector of the ball-end along the cutter centre axis line; $\mathbf{r}_{p}\left(x_{p}, y_{p}, z_{p}\right)$ is the vector of the tangent direction at the contact machining point on the machined surface; $\mathbf{n}\left(n_{x}, n_{y}, n_{z}\right)$ is the unit normal vector of the surface being machined at the point $\mathrm{P}$, and $\mathrm{R}$ is the radius of the ball-end cutter.

The equation (1) can be written in the component form as follows:

$$
\left\{\begin{array}{l}
x_{C_{o}}=x_{p}+R \times n_{x} \\
y_{C_{o}}=y_{p}+R \times n_{y} \\
z_{C_{o}}=z_{p}+R \times n_{z}
\end{array}\right.
$$

\subsection{Calculation of the path interval}

The path interval is defined as a distance between the contact point of adjacent cutting row or adjacent cutting cutter path when a ball-end cutter is used for milling. The path interval indicates the density of the cutter path; it affects the machining accuracy and machining efficiency.

Usually, the path interval $d$, the residual height $h$, the cutter effective cutting radius $R$ and the surface curvature radius along the row direction $\rho$ are closely interrelated. The path interval $d$ is the function of $h, R$, and $\rho$. In the case of a certain level of residual height, the path interval $d$ is determined by the curvature radius $\rho$ and the cutter effective cutting radius $R$. The relationship between the residual height $\mathrm{h}$ and the path interval $d$ is shown in Figure 4 in the case of machining a curved surface.

The mathematical expression of path interval is expressed as follows:

$$
d=\frac{\sqrt{4(R+\rho)^{2}(h+\rho)^{2}-\left[\rho^{2}+2 R \rho+(h+\rho)^{2}\right]^{2}}}{|h+\rho|}
$$

where $d$ is the path interval, $\mathrm{mm} ; R$ is the cutter effective cutting radius, mm; $\rho$ is the surface curvature radius along the row direction, $\mathrm{mm}$ (which has a positive value when the surface is convex, otherwise it has a negative value), and $h$ is the residual height, $\mathrm{mm}$.

The calculation process of path interval $d$ by means of equation (3) is very complicated when a new cutter path was generated during the process of machining a complex curved surface with the ball-end cutter because stability is hard to be guaranteed. Therefore, the equation (3) can be simplified for common use:

$$
d=2 \sqrt{h(2 R-h)}
$$

\section{NC programming}

The method of NC programming can be divided into manual programming (for simple shape surfaces) and computer automatic programming (especially for complex shape surfaces). The software packages for computer automatic programming are PowerMILL, Mastercam, Unigraphics NX, Cimatron, and HyperMILL. The PowerMILL software package is employed for the NC programming in this study.

The NC machining of the LSBG pinion tooth surface consists of four steps: rough machining, semi-finish machining, finish machining, and clearance angle machining. The parameters of the LSBG pinion NC machining are shown in Table 2. 
The operation of annular array of rough machining cutter path with the number of 9 PCS (9 teeth) among the symmetric centre axis has been done, and all rough machining cutter paths of the LSBG pinion have been generated. The semi-finish machining and the finish machining of the LSBG pinion are performed after the rough machining. The finish machining cutter paths of one cogging are shown in Figure 5.

Table 2 Parameters of the LSBG pinion NC machining

\begin{tabular}{|c|c|c|c|c|c|c|c|c|}
\hline \multirow[b]{2}{*}{ Number } & \multirow[b]{2}{*}{$\begin{array}{l}\text { Process } \\
\text { name }\end{array}$} & \multirow[b]{2}{*}{$\begin{array}{l}\text { Processing } \\
\text { area }\end{array}$} & \multicolumn{6}{|c|}{ Main cutting parameters } \\
\hline & & & $\begin{array}{c}\text { Spindle } \\
\text { rotation } \\
\text { velocity } \\
(\mathrm{rpm})\end{array}$ & $\begin{array}{l}\text { Feed rate } \\
(\mathrm{mm} / \mathrm{min})\end{array}$ & $\begin{array}{l}\text { Stepover } \\
(\mathrm{mm})\end{array}$ & $\begin{array}{l}\text { Tolerance } \\
(\mathrm{mm})\end{array}$ & $\begin{array}{c}\text { Thickness } \\
\text { (mm) }\end{array}$ & $\begin{array}{l}\text { Stepdown } \\
(\mathrm{mm})\end{array}$ \\
\hline 1 & $\begin{array}{l}\text { Rough } \\
\text { machining }\end{array}$ & Cogging & 1500 & 1000 & 0.2 & 0.10 & 0.10 & 0.2 \\
\hline 2 & $\begin{array}{l}\text { Semi-finish } \\
\text { machining }\end{array}$ & Cogging & 6000 & 2000 & 0.1 & 0.03 & 0.05 & 0.1 \\
\hline 3 & $\begin{array}{l}\text { Finish } \\
\text { machining }\end{array}$ & Cogging & 8000 & 2000 & 0.1 & 0.01 & 0 & 0.08 \\
\hline 4 & $\begin{array}{l}\text { Clearance } \\
\text { angle } \\
\text { machining }\end{array}$ & $\begin{array}{l}\text { The } \\
\text { bottom of } \\
\text { the tooth }\end{array}$ & 8000 & 2000 & 0.1 & 0.01 & 0 & 0.08 \\
\hline
\end{tabular}

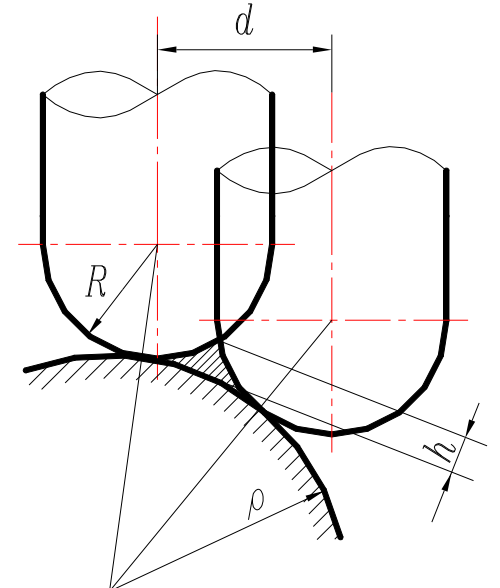

Fig. 4 Residual height and the path interval

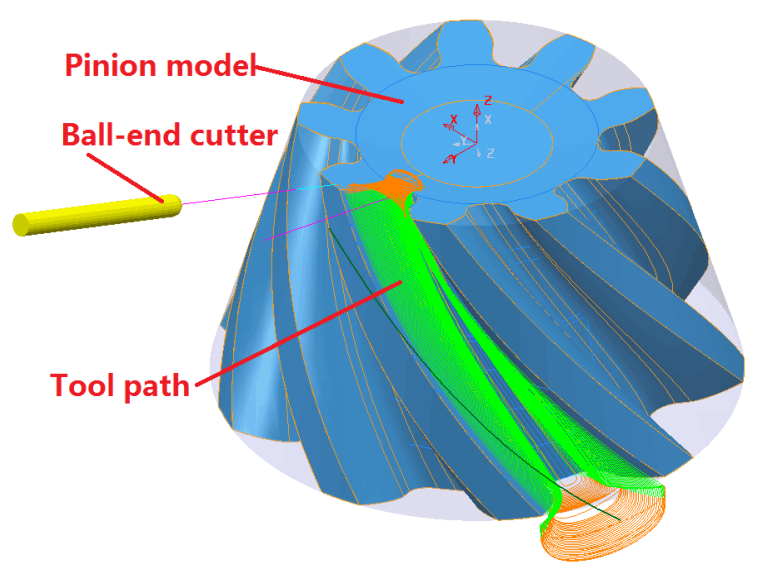

Fig. 5 Cutter path in the finish machining

\section{Coordinate transformation for the $\mathrm{NC}$ post processor}

The cutter location data file of the generated cutter path presented above just gives the information about the cutter position vector and the cutter axis vector in five-axis NC machining. In order to perform the final processing, the cutter location data file must be converted into the corresponding axis motion data of the five-axis vertical machining centre [40]. To solve each axis motion of the CNC machine tool, a kinematic model of the NC machine tool must be established. Motions along each axis of five-axis vertical machining centre can be solved according to the kinematic model of the machining centre and the cutter location data file. Two rotating axes of the DMG DMU40 monoBLOCK five-axis vertical machining centre are the $\mathrm{B}$ axis around which the cutter turns and the $\mathrm{C}$ axis around which the worktable rotates. The kinematic model of the DMG DMU40 is defined by the machine tool structure and the motion chain of the DMG DMU40 monoBLOCK five-axis vertical machining centre. 
The coordinate systems of the DMU40 five-axis vertical machining centre are established as shown in Figure 6. The workpiece coordinate system is denoted as $O_{w} X_{w} Y_{w} Z_{w}$, and that of the cutter as $\mathrm{O}_{\mathrm{t}} \mathrm{X}_{\mathrm{t}} \mathrm{Y}_{\mathrm{t}} \mathrm{Z}_{\mathrm{t}} \cdot \mathrm{O}_{\mathrm{m} 2} \mathrm{X}_{\mathrm{m} 2} \mathrm{Y}_{\mathrm{m} 2} \mathrm{Z}_{\mathrm{m} 2}$ is the coordinate system which is set up on the rotary axis $\mathrm{B}$, and the direction is consistent with the direction of the machine tool coordinate system. The origin point $\mathrm{O}_{\mathrm{m} 2}$ is the intersection of the cutter axis and the rotation axis of the $\mathrm{B}$ axis. $\mathrm{O}_{\mathrm{m} 1} \mathrm{X}_{\mathrm{m} 1} \mathrm{Y}_{\mathrm{m} 1} \mathrm{Z}_{\mathrm{m} 1}$ is the coordinate system which is set up on the rotary axis $\mathrm{C}$, and the direction is consistent with the direction of the machine tool coordinate system. The origin point $\mathrm{O}_{\mathrm{m} 1}$ can be arbitrarily selected on the rotation axis.

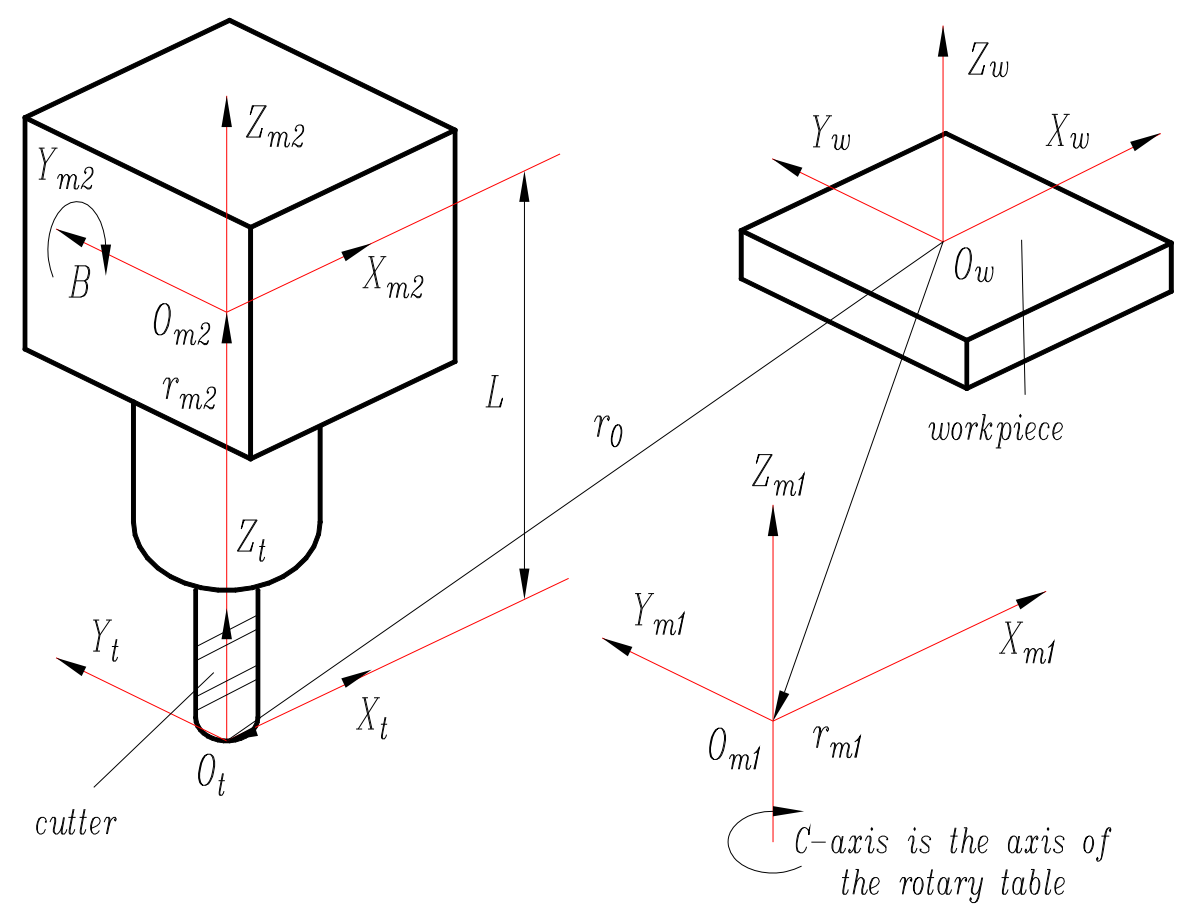

Fig.6 Coordinate systems of the NC machine tool

In the initial condition, the origin point $\mathrm{O}_{w}$ of the workpiece coordinate system $\mathrm{O}_{\mathrm{w}} \mathrm{X}_{\mathrm{w}} \mathrm{Y}_{\mathrm{w}} \mathrm{Z}_{\mathrm{w}}$ coincides with the origin point $\mathrm{O}_{\mathrm{t}}$ of the cutter coordinate system $\mathrm{O}_{t} \mathrm{X}_{t} \mathrm{Y}_{\mathrm{t}} \mathrm{Z}_{\mathrm{t}}$. The axis of the ball-end cutter is parallel to the $Z$ axis, and the direction of the workpiece coordinate system $\mathrm{O}_{\mathrm{w}} \mathrm{X}_{\mathrm{w}} \mathrm{Y}_{\mathrm{w}} \mathrm{Z}_{\mathrm{w}}$ is consistent with the direction of the machine tool coordinate system. $\mathrm{L}$ is the distance from the origin point $\mathrm{O}_{\mathrm{t}}$ of the cutter coordinate system $\mathrm{O}_{t} \mathrm{X}_{\mathrm{t}} \mathrm{Y}_{\mathrm{t}} \mathrm{Z}_{\mathrm{t}}$ to the origin point $\mathrm{O}_{\mathrm{m} 2}$ of the coordinate system $\mathrm{O}_{\mathrm{m} 2} \mathrm{X}_{\mathrm{m} 2} \mathrm{Y}_{\mathrm{m} 2} \mathrm{Z}_{\mathrm{m} 2}$; the position vector of the point $\mathrm{O}_{\mathrm{m} 2}$ in the cutter coordinate system $\mathrm{O}_{\mathrm{t}} \mathrm{X}_{\mathrm{t}} \mathrm{Y}_{\mathrm{t}} \mathrm{Z}_{\mathrm{t}}$ is $\boldsymbol{r}_{\boldsymbol{m} 2}(0,0, \mathrm{~L})$.

Suppose $\boldsymbol{r}_{\boldsymbol{m} \boldsymbol{I}}\left(\mathrm{m}_{\mathrm{x}}, \mathrm{m}_{\mathrm{y}}, \mathrm{m}_{\mathrm{z}}\right)$ is the origin point $\mathrm{O}_{\mathrm{m} 1}$ position vector of the coordinate system $\mathrm{O}_{\mathrm{m} 1} \mathrm{X}_{\mathrm{m} 1} \mathrm{Y}_{\mathrm{m} 1} \mathrm{Z}_{\mathrm{m} 1}$ in the workpiece coordinate system $\mathrm{O}_{\mathrm{w}} \mathrm{X}_{\mathrm{w}} \mathrm{Y}_{\mathrm{w}} \mathrm{Z}_{\mathrm{w}}$. The workpiece and the cutter are mutually independent in their movement in the five-axis $\mathrm{NC}$ machining process. Therefore, the vector $\boldsymbol{r}_{\boldsymbol{m} \boldsymbol{1}}\left(\mathrm{m}_{\mathrm{x}}, \mathrm{m}_{\mathrm{y}}, \mathrm{m}_{\mathrm{z}}\right)$ and the vector $\boldsymbol{r}_{\boldsymbol{m} 2}(0,0, \mathrm{~L})$ are the essential factors for establishing the kinematic model of the DMU40 monoBLOCK five-axis vertical machining centre; the cutter turns around the $\mathrm{B}$ axis and the worktable rotates around the $\mathrm{C}$ axis.

In the cutter coordinate system $\mathrm{O}_{t} \mathrm{X}_{\mathrm{t}} \mathrm{Y}_{\mathrm{t}} \mathrm{Z}_{\mathrm{t}},[0,0,1]^{\mathrm{T}}$ is the direction vector of the cutter axis, $[0,0,0]^{T}$ is the position vector of the cutter location point, $\boldsymbol{r}_{s}\left(\mathrm{~s}_{\mathrm{x}}, \mathrm{s}_{\mathrm{y}}, \mathrm{s}_{\mathrm{z}}\right)$ is the displacement vector of three translational axes $\mathrm{X}, \mathrm{Y}, \mathrm{Z}$ relative to the initial position, $\theta_{\mathrm{B}}$ (counter clockwise for a positive value) is the rotation angle of the axis $\mathrm{B}$ relative to the initial position, $\theta_{\mathrm{C}}$ (counter clockwise for a positive value) is the rotation angle of the axis $\mathrm{C}$ relative to the initial position, $\boldsymbol{u}\left(\mathrm{u}_{\mathrm{x}}, \mathrm{u}_{\mathrm{y}}, \mathrm{u}_{\mathrm{z}}\right)$ is the cutter axis direction vector of the workpiece coordinate system $\mathrm{O}_{\mathrm{w}} \mathrm{X}_{\mathrm{w}} \mathrm{Y}_{\mathrm{w}} \mathrm{Z}_{\mathrm{w}}$, and $\boldsymbol{r}_{p}\left(\mathrm{p}_{\mathrm{x}}, \mathrm{p}_{\mathrm{y}}, \mathrm{p}_{\mathrm{z}}\right)$ is the position vector of the cutter location point. 
The coordinate transformation relations are as follows: the cutter coordinate system $\mathrm{O}_{\mathrm{t}} \mathrm{X}_{\mathrm{t}} \mathrm{Y}_{\mathrm{t}} \mathrm{Z}_{\mathrm{t}}$ is rotated relative to the coordinate system $\mathrm{O}_{\mathrm{m} 2} \mathrm{X}_{\mathrm{m} 2} \mathrm{Y}_{\mathrm{m} 2} \mathrm{Z}_{\mathrm{m} 2}$, the coordinate system $\mathrm{O}_{\mathrm{m} 2} \mathrm{X}_{\mathrm{m} 2} \mathrm{Y}_{\mathrm{m} 2} \mathrm{Z}_{\mathrm{m} 2}$ is translated relative to the coordinate system $\mathrm{O}_{\mathrm{m} 1} \mathrm{X}_{\mathrm{m} 1} \mathrm{Y}_{\mathrm{m} 1} \mathrm{Z}_{\mathrm{m} 1}$, the coordinate system $\mathrm{O}_{\mathrm{m} 1} \mathrm{X}_{\mathrm{m} 1} \mathrm{Y}_{\mathrm{m} 1} \mathrm{Z}_{\mathrm{m} 1}$ is rotated relative to the workpiece coordinate system $\mathrm{O}_{\mathrm{w}} \mathrm{X}_{\mathrm{w}} \mathrm{Y}_{\mathrm{w}} Z_{\mathrm{w}}$. The formulas for a series of coordinate transformation relations are shown below.

$$
\begin{aligned}
& {\left[\begin{array}{llll}
p_{x} & p_{y} & p_{z} & 1
\end{array}\right]^{T}=\mathbf{T}\left(r_{m 1}\right) \mathbf{R}_{z}\left(-\theta_{C}\right) \mathbf{T}\left(\mathbf{r}_{s}-\mathbf{r}_{m 1}+\mathbf{r}_{m 2}\right) \mathbf{R}_{Y}\left(\theta_{B}\right) \mathbf{T}\left(-r_{m 2}\right)\left[\begin{array}{llll}
0 & 0 & 0 & 1
\end{array}\right]^{T}} \\
& {\left[\begin{array}{llll}
u_{x} & u_{y} & u_{z} & 0
\end{array}\right]^{T}=\mathbf{T}\left(r_{m 1}\right) \mathbf{R}_{z}\left(-\theta_{C}\right) \mathbf{T}\left(\mathbf{r}_{s}-\mathbf{r}_{m 1}+\mathbf{r}_{m 2}\right) \mathbf{R}_{Y}\left(\theta_{B}\right) \mathbf{T}\left(-r_{m 2}\right)\left[\begin{array}{llll}
0 & 0 & 1 & 0
\end{array}\right]^{T}}
\end{aligned}
$$

The transformation matrix of the coordinate transformations $\boldsymbol{R}_{z}\left(-\theta_{\mathrm{C}}\right), \boldsymbol{R}_{\boldsymbol{y}}\left(\theta_{\mathrm{B}}\right), \boldsymbol{T}\left(\mathrm{r}_{\mathrm{m} 1}\right)$, $\boldsymbol{T}\left(-\mathrm{r}_{\mathrm{m} 2}\right)$, and $\boldsymbol{T}\left(\mathrm{r}_{\mathrm{s}}-\mathrm{r}_{\mathrm{m} 1}+\mathrm{r}_{\mathrm{m} 2}\right)$ are as follows.

$$
\begin{gathered}
\boldsymbol{R}_{z}\left(-\theta_{C}\right)=\left[\begin{array}{cccc}
\cos \theta_{C} & \sin \theta_{C} & 0 & 0 \\
-\sin \theta_{C} & \cos \theta_{C} & 0 & 0 \\
0 & 0 & 1 & 0 \\
0 & 0 & 0 & 1
\end{array}\right], \boldsymbol{R}_{Y}\left(\theta_{B}\right)=\left[\begin{array}{cccc}
\cos \theta_{B} & 0 & \sin \theta_{B} & 0 \\
0 & 1 & 0 & 0 \\
\sin \theta_{B} & 0 & \cos \theta_{B} & 0 \\
0 & 0 & 0 & 1
\end{array}\right] \\
\boldsymbol{T}\left(r_{m 1}\right)=\left[\begin{array}{llll}
1 & 0 & 0 & m_{x 1} \\
0 & 1 & 0 & m_{y 1} \\
0 & 0 & 1 & m_{z 1} \\
0 & 0 & 0 & 1
\end{array}\right], \boldsymbol{T}\left(-r_{m 2}\right)=\left[\begin{array}{cccc}
1 & 0 & 0 & 0 \\
0 & 1 & 0 & 0 \\
0 & 0 & 1 & -L \\
0 & 0 & 0 & 1
\end{array}\right], \boldsymbol{T}\left(\boldsymbol{r}_{s}-\boldsymbol{r}_{m 1}+\boldsymbol{r}_{m 2}\right)=\left[\begin{array}{cccc}
1 & 0 & 0 & s_{x}-m_{x} \\
0 & 1 & 0 & s_{y}-m_{y} \\
0 & 0 & 1 & s_{z}-m_{z}+L \\
0 & 0 & 0 & 1
\end{array}\right]
\end{gathered}
$$

The kinematic model of the DMU40 monoBLOCK five-axis vertical machining centre, with the C-B type structure in which the cutter turns around the B axis and the worktable rotates around the $\mathrm{C}$ axis, can be defined by equation (5) and equation (6) as follows.

$$
\begin{aligned}
& {\left[\begin{array}{c}
p_{x} \\
p_{y} \\
p_{z} \\
1
\end{array}\right]=\left[\begin{array}{c}
\left(s_{x}-m_{x}\right) \cos \theta_{C}+\left(s_{y}-m_{y}\right) \sin \theta_{C}+m_{x_{1}}-L \cos \theta_{C} \sin \theta_{B} \\
-\left(s_{x}-m_{x}\right) \sin \theta_{C}+\left(s_{y}-m_{y}\right) \cos \theta_{C}+m_{y_{1}}+L \sin \theta_{C} \sin \theta_{B} \\
s_{z}-m_{z}+L+m_{z_{1}}-L \cos \theta_{B} \\
1
\end{array}\right]} \\
& {\left[\begin{array}{l}
u_{x} \\
u_{y} \\
u_{z} \\
0
\end{array}\right]=\left[\begin{array}{c}
\cos \theta_{C} \sin \theta_{B} \\
-\sin \theta_{C} \sin \theta_{B} \\
\cos \theta_{B} \\
0
\end{array}\right]}
\end{aligned}
$$

The five movements in the C-B type structure of the DMU40 monoBLOCK five-axis vertical machining centre can be solved by equation (7) and equation (8). The displacement calculation formulas of five movements are shown as follows:

$$
\begin{aligned}
& s_{x}=\left(p_{x}+m_{x_{1}}\right) \cos \theta_{C}-\left(p_{y}+m_{y_{1}}\right) \sin \theta_{C}+m_{x}+m_{y} \tan \theta_{C}+L \sin \theta_{B} \\
& s_{y}=\left(p_{x}+m_{x_{1}}\right) \sin \theta_{C}+\left(p_{y}-m_{y_{1}}\right) \cos \theta_{C} \\
& s_{z}=p_{z}-m_{z}-L-m_{z_{1}}+L \cos \theta_{B} \\
& \theta_{B}=\arccos \left(u_{z}\right) \quad\left(-\pi / 2 \leq \theta_{B} \leq \pi / 2\right) \\
& \theta_{C}=\operatorname{arccot}\left(-u_{x} / u_{y}\right)-k_{A} \pi \quad\left(k_{A}=0 \text { or } 1\right)
\end{aligned}
$$

where $k_{A}$ is the integer. The value of $k_{A}$ is 0 or 1 . 
Two solutions of $\theta_{C}$ are obtained by using the inverse trigonometric function to solve equation (13). The solution is unique when the value of the $\mathrm{C}$ axis angle can be satisfied with $\sin \theta_{C}=u_{y} / \sin \theta_{B}$ while $\cos \theta_{C}=u_{x} / \sin \theta_{B}$.

\section{Experimental verification of five-axis NC machining}

The operation of annular array of finish machining cutter path with the number of 9 PCS along the symmetric centre axis has been done, and the whole finish machining cutter paths of the LSBG pinion has been generated.

The NC code was created by using the cutter paths generated in the PowerMILL software package through the post processor and by selecting the $\mathrm{NC}$ control system of DMU40 monoBLOCK. However, the created NC code is generally not suitable for being directly applied in the real NC machining because the created NC code may cause collision, overcutting, and under cutting [33]. Therefore, the created NC code must be verified before real NC machining is performed. A traditional verification method is the trial-machining: the $\mathrm{NC}$ code is entered into the NC machine tool and workpieces made of foam, plastic or other soft materials are machined, then a real workpiece is machined on the NC machine tool. Obviously, a lot of manpower, material and money are wasted by using the trial-machining method. At present, the NC geometry simulation method can eliminate the shortcoming of trial-machining method and it can also shorten the product development period and increase productivity.

The geometry simulation of the LSBG pinion tooth surface in the NC machining is shown in Figure 7. Collision, overcutting, and undercutting do not occur during the NC machining of the LSBG pinion.

The installation and clamping of the LSBG pinion on the DMU40 monoBLOCK fiveaxis vertical machining centre are shown in Figure 8. The four-jaw chuck was used for positioning and clamping, and the trial-machining method was used for cutter setting. The coordinate position of the cutter tip point on the $\mathrm{CNC}$ machine tool worktable are adjusted by the electronic hand wheel of the DMU40 monoBLOCK while the coordinate setting of the $\mathrm{Z}$ axis direction was measured by using a feeler gauge.

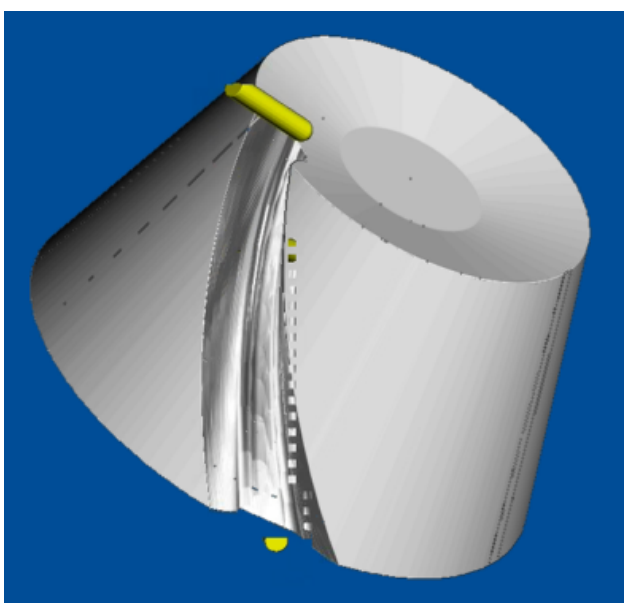

Fig. 7 Geometry simulation

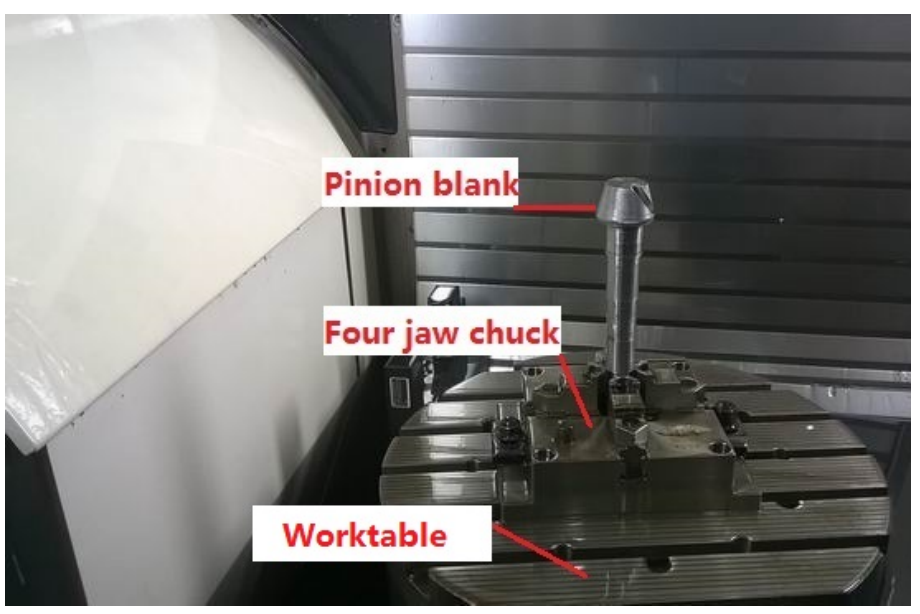

Fig. 8 Installation and clamping on the worktable 
The rough machining, semi-finish machining, finish machining, and clearance angle machining of the LSBG pinion were carried out by calling the corresponding NC code. One of the processes of rough machining is illustrated in Figure 9. An oily cutting fluid was used for lubrication and cooling during the whole NC machining process.

Finally, a prototype, shown in Figure 10, was produced.

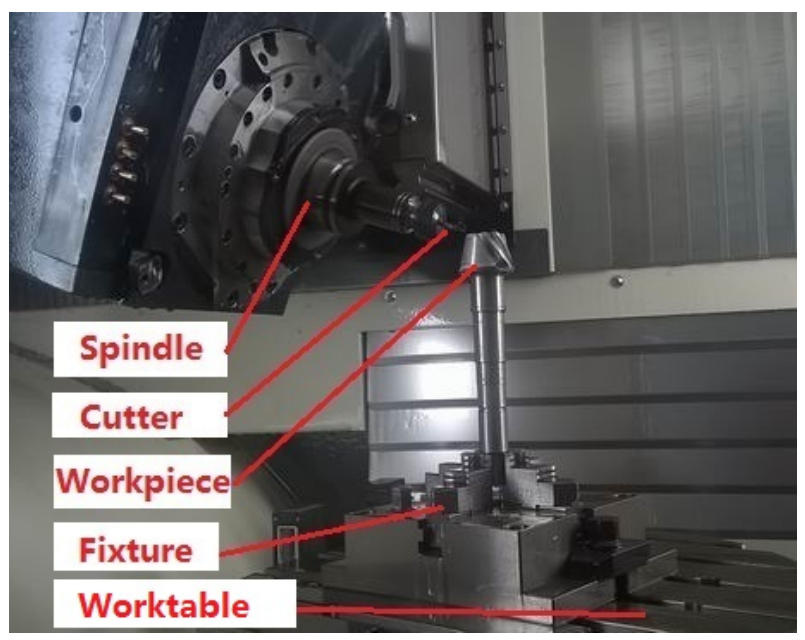

Fig. 9 Machining of the LSBG pinion - a photo

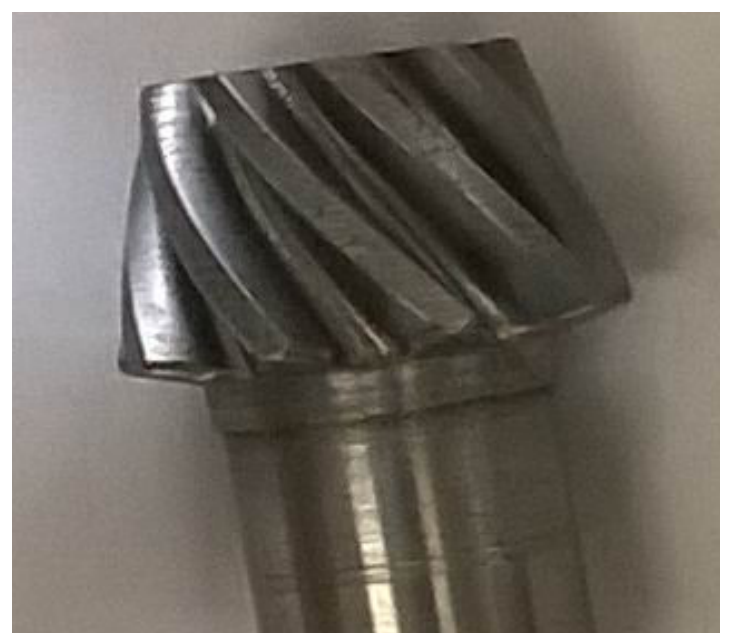

Fig. 10 Photo of the produced LSBG pinion prototype

\section{Conclusions}

(1) The cutter path and the path interval were determined according to the relationships between the ball-end cutter and the tooth surface of LSBG. The cutter paths in the NC machining of the LSBG pinion were generated.

(2) A kinematic model of a DMG DMU40 monoBLOCK five-axis vertical machining centre was established. The NC code was generated by converting the cutter location file into $\mathrm{CNC}$ five-axis motion data through the post processor coordinate transformation formula.

(3) A prototype of tapered teeth LSBG pinion was produced on the DMG DMU40 monoBLOCK five-axis vertical machining centre, the prototype can be used for experiments in future research on LSBG.

(4) The method of machining the LSBG tooth flank on a general five-axis NC machine was presented only for the prototype, while the machining efficiency for a real product is still in the scope of further research.

\section{Acknowledgments}

This study was supported by the National Natural Science Foundation of China through the grants No.51475399 and No.51375411, the Fujian Science and Technology Platform Project of China, grant No.2016H2003, and High level talent research project of Xiamen University of Technology grant No.YKJ17016R.

\section{Nomenclature}

3D Three-dimensional

b Face width

CNC Computer numerical control
PCS Pieces

$R \quad$ Cutter effective cutting radius(the radius of the ball-end cutter)

SBG Spiral bevel gear 
$D_{\mathrm{p}} \quad$ Pitch circle diameter

d Path interval

$h \quad$ Residual height

$h_{\mathrm{a}} \quad$ Addendum

$h_{\mathrm{f}} \quad$ Dedendum

$k_{A} \quad$ Integer

LSBG Logarithmic spiral bevel gear

$m \quad$ Exterior transverse modulus

NC Numerical control

n
Unit normal vector of being processed surface
Vector of the ball-end along the cutter centre axis line

Vector of the tangent direction at the contact machining point on the processed surface

Number of teeth

Pressure angle

Spiral angle

Reference cone angle

Surface curvature radius along the row direction

$\sum \quad$ Shaft angle

$\Phi_{\mathrm{R}} \quad$ Face width coefficient

\section{REFERENCES}

[1] W.Q.Zhang, B.K.Chen, X.D.Guo et al., A motion control method for face hobbing on CNC hypoid generator, Mechanism and Machine Theory, 92 (2015) 127-143. https://doi.org/10.1016/j.mechmachtheory.2015.05.008

[2] Y.Xing, S.F.Qin, T.Y.Wang et al., Subdivision surface modeling for spiral bevel gear manufacturing, Int J Adv Manuf Technol, 53 (2011):63-70. https://doi.org/10.1007/s00170-010-2813-1

[3] S.H.Suh, W.S.Jih, H.D.Hong et al., Sculptured surface machining of spiral bevel gears with CNC milling, International Journal of Machine Tools \& Manufacture, 41 (2001) 833-850. https://doi.org/10.1016/S0890-6955(00)00104-8

[4] C.Y.LIN, C.B.Tsay, Z.H.Fong, Mathematical model of spiral bevel and hypoid gears manufactured by the modified roll method, Mech.Mach.Theory, 32(2)(1997)121-136. https://doi.org/10.1016/S0094-114X(96)00043-2

[5] X.Y.Yang and J.Y.Tang, Research on manufacturing method of CNC plunge milling for spur facegear,Journal of Materials Processing Technology 214 (2014) 3013-3019. https://doi.org/10.1016/j.jmatprotec.2014.07.010

[6] C.Y.LIN, C.B.TSAY and Z.H.FONG, Computer-aided manufacturing of spiral bevel and hypoid gears with minimum surface-deviation, Mech. Mach. Theory, 33(6)(1998) 785-803. https://doi.org/10.1016/S0094-114X(97)00101-8

[7] Y.P.Shih and Z.H.Fong. Flank correction for spiral bevel and hypoid gears on a six-axis CNC hypoid generator, Journal of Mechanical Design, 130(6)(2008) 062604:1-11.

[8] P.Y.Wang and Z.H.Fong, Adjustability improvement of face-milling spiral bevel gears by modified radial motion (MRM) method, Mechanism and Machine Theory, 40 (2005)69-89. https://doi.org/10.1016/j.mechmachtheory.2004.05.011

[9] P.Y.Wang and Z.H.Fong, Mathematical Model of Face-Milling Spiral Bevel Gear with Modified Radial Motion (MRM) Correction.Mathematical and Computer Modeling, 41 (2005) 1307-1323. https://doi.org/10.1016/j.mcm.2004.07.015

[10] W.K.Jehng, Computer solid modeling technologies applied to develop and form mathematical parametric tooth profiles of bevel gear and skew gear sets, Journal of Materials Processing Technology, 122 (2002) 160-172. https://doi.org/10.1016/S0924-0136(01)01258-4

[11] G.Sheveleva, A.E.Volkov, V.Medvedev, Algorithms for analysis of meshing and contact of spiral bevel gears, Mechanism and Machine Theory, 42 (2007) 198-215. https://doi.org/10.1016/j.mechmachtheory.2006.02.009

[12] N.Kato, M.Tsutsumi, R.Sato, Analysis of circular trajectory equivalent to cone-frustum milling in fiveaxis machining centers using motion simulator, International Journal of Machine Tools \& Manufacture, 64(2013)1-11. https://doi.org/10.1016/j.ijmachtools.2012.07.013 
Tooth Flank of a Logarithmic Spiral Bevel Gear Pinion

[13] J.C.J. Chiou, Accurate tool position for five-axis ruled surface machining by swept envelope approach, Computer-Aided Design, 36 (2004) 967-974. https://doi.org/10.1016/j.cad.2003.10.001

[14] L.M.Zhu, G.Zheng, H.Ding. Formulating the swept envelope of rotary cutter undergoing general spatial motion for multi-axis NC machining,International Journal of Machine Tools \& Manufacture, 49(2009)199-202. https://doi.org/10.1016/j.jimachtools.2008.10.004

[15] Q. Li and H.B.Yan, The Logarithmic spiral bevel gear meshing theory, Beijing: Metallurgical Industry Press (2012)(In Chinese).

[16] J.T.Alves, M.Guingand, J.P.Vaujany, Designing and Manufacturing Spiral Bevel Gears Using 5-Axis Computer Numerical Control CNC Milling Machines, Journal of Mechanical Design,135(2013) 024502:1-6.

[17] T.M.Xiang, L.Z.Gu and L.L.Xiao. Accurate modeling of logarithmic spiral bevel gear based on the tooth flank formation and Boolean addition operation, Proc IMechE Part B:J Engineering Manufacture, 230(9)(2016) 1650-1658. https://doi.org/10.1177/0954405416660998

[18] T.M.Xiang, L.Z.Gu and J.M.Xu. The meshing angular velocity and tangential contact force simulation for logarithmic spiral bevel gear based on Hertz elastic contact theory, Journal of Mechanical Science and Technology,30(8) (2016) 3441-3452. https://doi.org/10.1007/s12206-016-0702-8

[19] R.L.Tan, B.K.Chen, C.Y.Peng et al., Study on spatial curve meshing and its application for logarithmic spiral bevel gears. Mech Mach Theory, 86(4)(2015) 172-190.

https://doi.org/10.1016/j.mechmachtheory.2014.11.023

[20] K.Huang, Y.S.Xiong, Q.CHEN et al., The Parametric Modeling Method Research of Logarithmic Spiral Bevel Gear, Modular Machine Tool \& Automatic Manufacturing Technique,57(10)(2015)8-11. (In Chinese)

[21] Q.Li, G.X.Zhang, J.Meng et al., Proposed of High-tooth Logarithmic Spiral Bevel Gear Process Route, Coal Mine Machinery, 35(07)(2014)141-142. (In Chinese)

[22] L.Li, H.Yan. Machining simulation of high-tooth logarithmic spiral bevel gear, Hydromechatronics Engineering, 42(24)(2014)103-106. https://doi.org/10.4028/www.scientific.net/AMM.644-650.642

[23] Q.Li, H.Yan, H.B.Yan et al., The proposed of high-tooth logarithmic spiral bevel gear process route, Manufacturing Automation, 36(10)(2014)60-63(In Chinese).

[24] Q.LI, H.N.ZHANG, L.T.WANG et al., Study on Tooth Processing Method of Logarithmic Spiral Bevel Gear, Coal Mine Machinery, 36(9)(2015)155-157(In Chinese).

[25] Q.LI, H.N.ZHANG, H.B.YAN et al., Differential Motion Analysis of Hobbing Process Logarithmic Spiral Bevel Gear, Coal Mine Machinery, 36(2)(2015)146-148(In Chinese).

[26] H.C.JUNG, H.J.Son and Y.G.Jung, Development of tool-path generation module for 5-axis control machining of impellers,J. Cent. South Univ. 19 (2012) 3424-3429.

https://doi.org/10.1007/s11771-012-1424-4

[27] H.T.Young and L.C.Chuang, An Integrated Machining Approach for a Centrifugal Impeller, Int J Adv Manuf Technol, 21 (2003) 556-563. https://doi.org/10.1007/s00170-002-1382-3

[28] P.Lim, Optimization of the rough cutting factors of impeller with five-axis machine using response surface methodology, Int J Adv Manuf Technol, 45 (2009)821-829.

https://doi.org/10.1007/s00170-009-2011-1

[29] F.J.Meng, Z.T.Chen, R.F.Xu et al., Optimal barrel cutter selection for the CNC machining of blisk, Computer-Aided Design, 53 (2014) 36-45. https://doi.org/10.1016/j.cad.2014.03.006

[30] B.Ann, P.D.Brown, C.Robert et al., Integrated computational materials engineering from a gas turbine engine perspective, Integrating Materials and Manufacturing Innovation, 13(3)(2014)1-24.

[31] L.C.Chuang and H.T.Young, Integrated rough machining methodology for centrifugal impeller manufacturing, Int J Adv Manuf Technol, 34 (2007)1062-1071. https://doi.org/10.1007/s00170-006-0675-3

[32] S.Ding, M.A.Mannan, A.N.Poo. Oriented bounding box and octree based global interference detection in 5-axis machining of free-form surfaces, Computer-Aided Design, 36 (2004)1281-1294. https://doi.org/10.1016/S0010-4485(03)00109-X

[33] T.D.Tang. Algorithms for collision detection and avoidance for five-axis NC machining: A state of the art review, Computer-Aided Design, 51 (2014) 1-17. https://doi.org/10.1016/j.cad.2014.02.001

[34] Q.Q.Wu, The Research on the key technology of the five axis NC machining of YL8000X Type Flue Gas Turbine Moving Blades, Lanzhou University of Technology,Lanzhou,China,2014. (In Chinese) 
[35] W.F.Gan, J.Z.Fu, H.Y.Shen et al., Five-axis tool path generation in CNC machining of T-spline surfaces, Computer-Aided Design, 52 (2014) 51-63. https://doi.org/10.1016/j.cad.2014.02.013

[36] Z.W.Lin, J.Z.Fu, H.Y.Shen et al, Smooth contour-parallel tool path generation for high-speed machining through a dual offset procedure, Int J Adv Manuf Technol, 81(2015) 1233-1245. https://doi.org/10.1007/s00170-015-7275-Z

[37] J.N.Lee and R.S.Lee, Interference-free tool path generation using enveloping element for five-axis machining of spatial cam, Journal of Materials Processing Technology, 187 (2007) 10-13. https://doi.org/10.1016/j.jmatprotec.2006.11.200

[38] B.K.Fussell, R.B.Jerard, J.G. Hemmett, Modeling of cutting geometry and forces for 5-axis sculptured surface machining, Computer-Aided Design, 35(2003)333-346. https://doi.org/10.1016/S0010-4485(02)00055-6

[39] Y.Z.Lin, Y.L.Shen, Enhanced virtual machining for sculptured surfaces by integrating machine tool error models into NC machining simulation, International Journal of Machine Tools \& Manufacture, 44 (2004) 79-86. https://doi.org/10.1016/j.ijmachtools.2003.08.003

[40] Y.Wang, Research of five-axis linkage NC machining complex curved surface, University of Science and Technology Liaoning, Shenyang, 2013. (In Chinese)

Submitted: $\quad 5.12 .2016$

Accepted: $\quad 30.8 .2017$
Tieming Xiang

School of Mechanical \& Automotive

Engineering, Xiamen University of Technology. Xiamen, 361024, China

Jixiang Yi

Engineering training centre, Xiamen University of

Technology, 361024, China

Wuxiong $\mathrm{Li}$

School of Automotive and Machinery, Huizhou Economics and Polytechnic College, 516057, China 